\title{
Jesús Martín-Barbero e os mapas essenciais para compreender a comunicação
}

\author{
Maria Immacolata Vassallo de Lopes \\ Doutora; Universidade de São Paulo, SP, Brasil \\ immaco@usp.br
}

\section{Resumo}

A obra de Jesús Martín-Barbero é conhecida por realizar deslocamentos e rupturas. Deslocamentos dos lugares tradicionais de onde são feitas as perguntas. Rupturas com as respostas reducionistas e maniqueístas "à direita e à esquerda". $O$ resultado pode ser sintetizado num trabalho de construção teórico-metodológica conhecido como mapa noturno, uma cartografia para explorar as mediações - é um marco a partir do qual se estuda as novas complexidades nas relações entre comunicação, cultura e política. $O$ artigo tem teor epistemológico e metodológico, com respeito aos conceitos e processos de mediação. Com tal objetivo, analisamos os vários mapas metodológicos das mediações que têm acompanhado as mudanças das relações estruturais entre comunicação e sociedade e levado ao aperfeiçoamento da teoria das mediações.

\section{Palavras-chave}

Mediações. Mapas. Jesús Martín-Barbero. Metodologia. Teoria.

\section{Introdução: conceito de mediação, um conceito em construção}

0 artigo tem teor epistemológico e metodológico, com respeito aos conceitos e aos processos de mediação. Com tal objetivo, analisamos os vários mapas metodológicos das mediações que foram cartografados acompanhando as mudanças históricas das relações entre comunicação e sociedade, o que tem levado ao aperfeiçoamento da teoria das mediações.

A teoria barberiana das mediações não se confunde com uma teoria da recepção e seu alcance está em compreender o inteiro processo da comunicação, tal como é concebido dentro de cada um dos mapas propostos. 
Partimos de um conjunto de princípios atribuídos por Martín-Barbero ao conceito de mediação:

a) a comunicação hoje é uma questão de mediações mais do que de meios de comunicação;

b) a mediação constitui uma perspectiva teórica compreensiva tanto dos processos de produção, do produto, como da recepção;

c) todo o processo de comunicação é articulado a partir das mediações.

Acompanhando temporalmente o conceito, notamos que:

a) a mediação é inicialmente vista como uma perspectiva de investigação sobre e a partir da recepção;

b) afirma-se progressivamente a importância da mediação para uma teoria da comunicação;

c) não há uma definição única de mediação;

d) mediação é uma noção plural: mediações.

Como afirma Martín-Barbero e Sonia Munhoz (1992, p. 20):

As mediações são esse 'lugar' de onde é possível compreender a interação entre o espaço da produção e o da recepção: o que [a mídia] produz não responde unicamente a requerimentos do sistema industrial e a estratagemas comerciais, mas também a exigências que vêm da trama cultural e dos modos de ver.

\section{Mapas metodológicos da mediação: da mediação cultural da comunicação à mediação comunicativa da cultura}

A leitura das mediações que o próprio autor propõe é por meio dos sucessivos mapas das mediações que são apresentados nas introduções das diferentes publicações de De los medios a las mediaciones (MARTÍN-BARBERO, 1987; 1998; 2010a)¹.

É fundamental acompanhar as modificações que os mapas das mediações apresentam ao longo da obra barberiana. Por isso, não há uma definição única de mediação, uma vez que ela parece ser uma noção movente, que acompanha permanentemente as transformações da sociedade e especificamente as da comunicação.

\footnotetext{
${ }^{1}$ Esse acompanhamento pode ser feito através das três introduções às diferentes edições do livro Dos meios às mediações (MARTÍN-BARBERO, 1987; 1998; 2010a). Até agora, são três introduções: de 1987, da primeira edição, publicada pela Editora Gustavo Gili, Barcelona; de 1998, da quinta edição, publicada pelo Convênio Andrés Bello, Bogotá; e de 2010, publicado por Anthropos Editorial, Barcelona e Universidad Autónoma Metropolitana de México. E também no pequeno livro Introducciones de los medios a las mediaciones, publicado pela Fundação Friedrich Ebert (MARTíN-BARBERO, 2010b).
} 
Por ser a sociedade contemporânea uma sociedade da comunicação generalizada (VATTIMO, 1992), são os processos comunicacionais enquanto operadores de sentido e o mercado como operador de valor; que movem, por meio de suas contradições e ambivalências, os vínculos societais entre os sujeitos.

Daí o primeiro mapa metodológico em que Martín-Barbero (1987) propõe o enfoque epistemológico da comunicação a partir da cultura ou o estudo das mediações culturais da comunicação.

É o que se vê representado na Figura 1.

Figura 1 - Primeiro mapa metodológico das mediações, de 1987

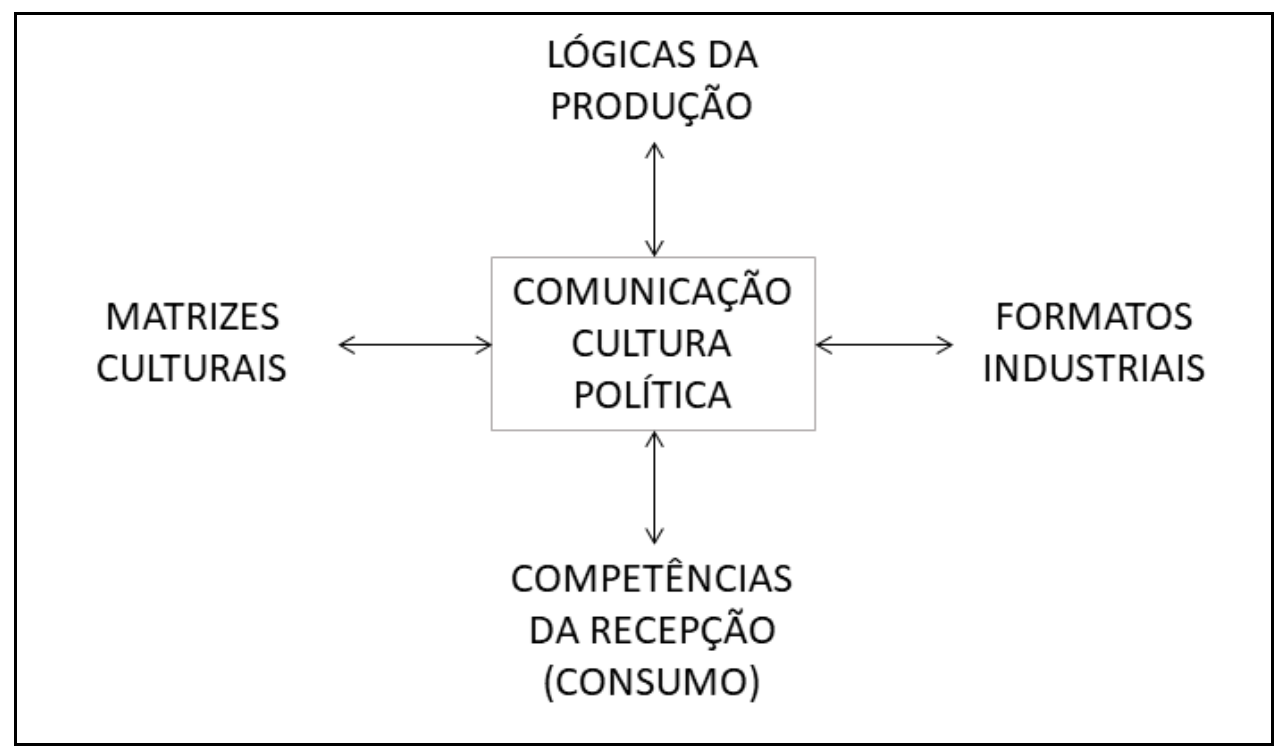

Fonte: Elaborado pela autora a partir de Martín-Barbero (1987). Introducción 1.

No centro do mapa estão as mediações constitutivas ou fundantes: comunicação, cultura e política. Elas remetem a dois eixos: o diacrônico ou histórico, entre matrizes culturais e formatos industriais; e o sincrônico, entre lógicas da produção e competências da recepção (consumo).

O segundo mapa é do final dos anos 1990, quando fica evidente uma complexa teoria das mediações que ultrapassa a configuração de uma teoria da recepção. 0 mapa agora tem por objetivo o estudo da cultura a partir da comunicação, deslocando o estudo das mediações culturais da comunicação para o das mediações comunicativas da cultura. 0 olhar não se inverte no sentido de ir das mediações aos meios, senão da cultura à comunicação. É a própria noção de comunicação que é repensada. Passa-se a dar mais densidade epistemológica de conhecer o que vem da comunicação. 
É o que mostra a Figura 2.

Figura 2 - Segundo mapa metodológico das mediações, de 1998

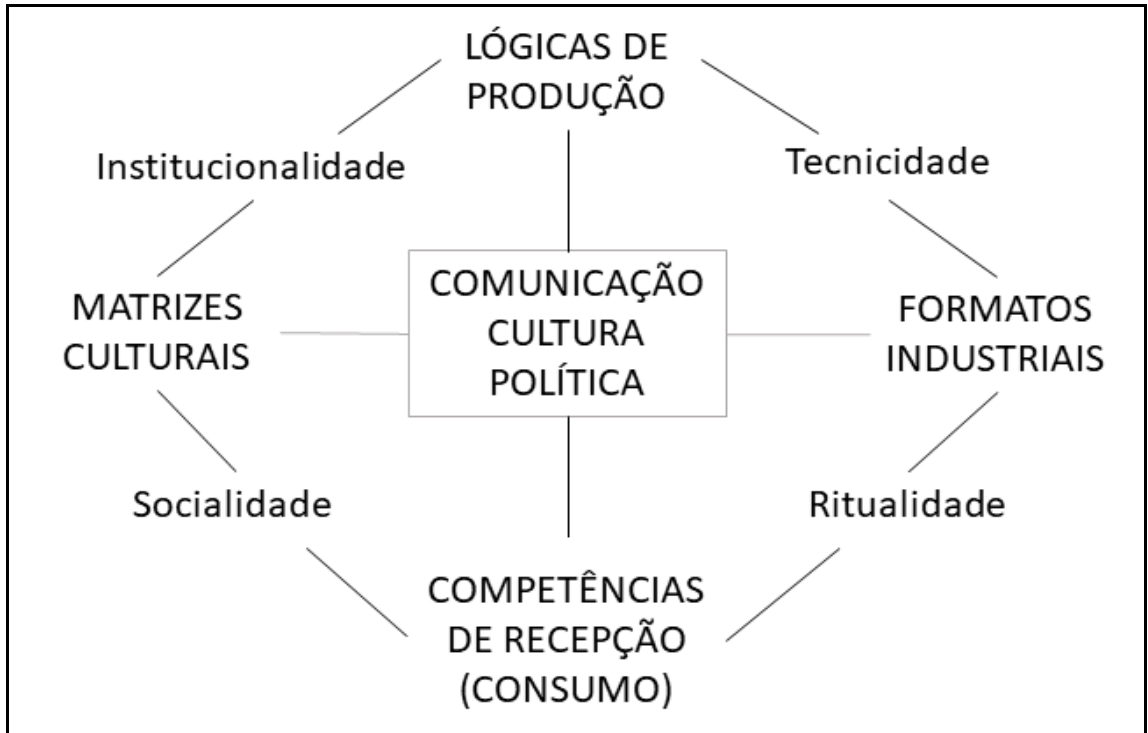

Fonte: Adaptado de Martín-Barbero (1998; 2001). Introducción 2.

Por meio deste mapa, é possível operacionalizar a análise de qualquer fenômeno social que relaciona comunicação, cultura e política, impondo-se como uma dimensão da articulação entre produtores, mídia, mensagens, receptores e cultura.

A mediação deve ser entendida como o processo estruturante que configura e reconfigura tanto a lógica da produção quanto a lógica dos usos. Ela exige pensar ao mesmo tempo o espaço da produção, assim como o tempo do consumo, ambos articulados pela vida cotidiana (usos/consumo/práticas) e pela especificidade dos dispositivos tecnológicos e discursivos das mídias envolvidas.

A necessidade de decoupage do conceito a fim de torná-lo metodologicamente manejável; leva-nos a afirmar os princípios que se seguem.

A mediação tem uma natureza triádica indissolúvel - cultura, comunicação, política a que chamamos mediações constituintes ou fundantes, porque:

Mais do que objetos de políticas, a comunicação e a cultura constituem hoje um campo primordial de batalha política: o estratégico cenário que exige que a política recupere sua dimensão simbólica - sua capacidade de representar o vínculo entre os cidadãos, o sentimento de pertencimento a uma comunidade - para enfrentar a erosão da ordem coletiva (MARTÍNBARBERO, 2001, p. 15). 
A mediação é um espaço que coloca em relação dialética as lógicas da produção e do consumo, os formatos industriais e as matrizes culturais. 0 esquema também se move em dois eixos: o diacrônico, ou histórico de longa duração - entre as matrizes culturais e os formatos industriais; e o sincrônico, entre as lógicas de produção e as competências de recepção. A novidade é que estas constituem quatro mediações básicas que estão articuladas através de submediações ou múltiplas mediações.

A relação entre as matrizes culturais e a lógica da produção é mediada por diferentes regimes de institucionalidade, enquanto a relação entre as matrizes culturais e as competências da recepção é mediada por várias formas de socialidade. Entre a lógica da produção e os formatos industriais media a tecnicidade, e entre os formatos e as competências da recepção media a ritualidade.

Não parece ser por acaso que, de um ponto de vista sistêmico, o objeto de estudo de Martín-Barbero seja a mediação, em primeiro lugar, como tecido de processos e materialidades da comunicação em um ambiente social e cultural, e em segundo, como um sistema de "des-coberta" de falsas polaridades. E nem é por acaso que todo objeto de estudo possa ser metodologicamente tratado por um pesquisador a partir de uma perspectiva da mediação.

A importância desse mapa está em reconhecer que a comunicação está mediando todas as formas da vida cultural e política da sociedade. Portanto, o olhar não se inverte no sentido de ir dos meios para as mediações e nem das mediações aos meios, senão para ver a complexa teia de múltiplas mediações. Foi necessário ao autor repensar a própria noção de comunicação, noção essa que sai do paradigma da engenharia e se liga com as interfaces, com os nós das interações, com a comunicação-interação, com a comunicação intermediada ${ }^{2}$. E porque a linguagem é cada vez mais intermediada, o estudo deve ser claramente interdisciplinar. Ou seja, trata-se de uma epistemologia que coloca em crise o próprio objeto de estudo.

Segundo o autor, o que existia era que a identidade da comunicação era achada nos meios e, hoje, ela não se dá somente nos meios. A comunicação ocorre na interação que possibilita a interface de todos os sentidos, portanto, é uma intermediação, que é um conceito para pensar a hibridização das linguagens e dos meios.

\footnotetext{
${ }^{2} \mathrm{O}$ deslocamento da pesquisa em comunicação para a pesquisa das mediações, na América Latina, é de certo modo análoga ao deslocamento dos estudos da informação para os estudos dos signos, na França, e dos estudos da informação para os estudos dos media, na Alemanha (BASTOS, 2012).
} 
Essa é a situação que marca a sociedade contemporânea que, com sua "[...] mutação tecnológica, passou a configurar um novo ecossistema comunicativo [...]" (MARTínBARBERO, 2010a, p. 222).

É o que mostra a Figura 3.

Figura 3 - Terceiro mapa metodológico das mediações, de 2010

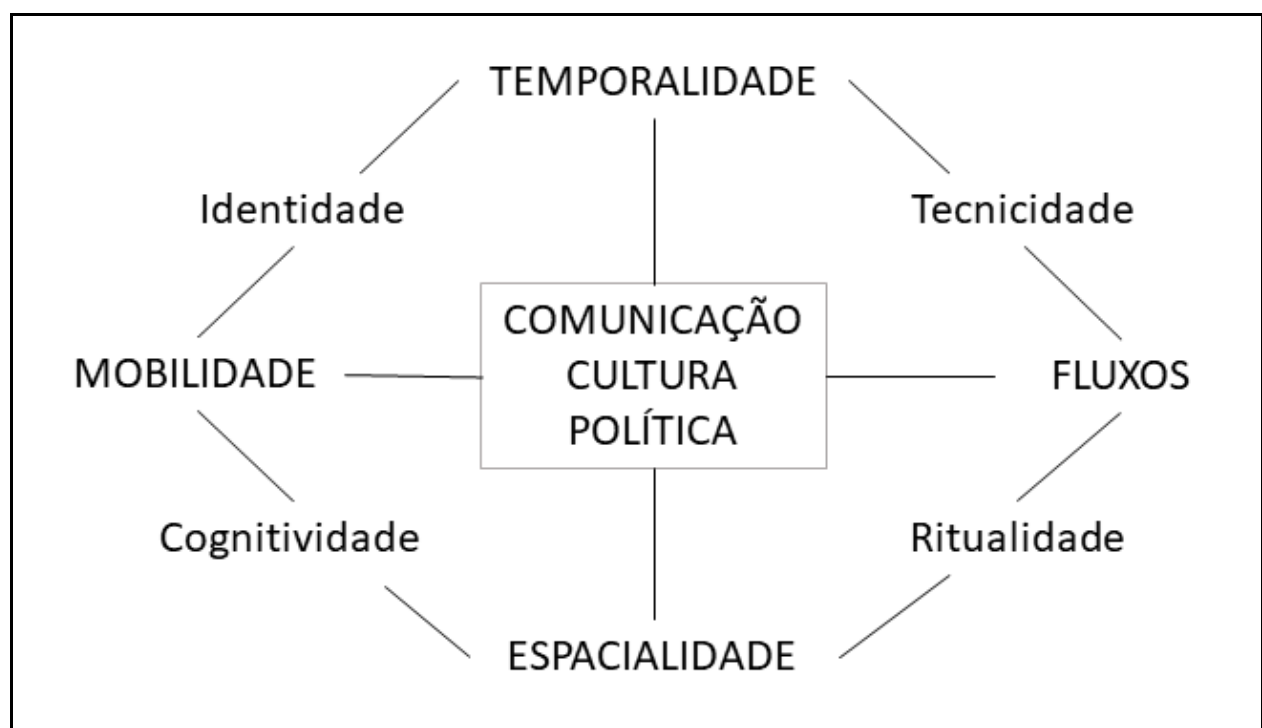

Fonte: Adaptado de Martín-Barbero (2009a; 2009b; 2010a). Introducción 3.

Focalizando apenas os eixos vertical e horizontal, esse terceiro mapa vincula os anteriores com a investigação das mutações culturais contemporâneas, cujas mediações básicas são a temporalidade e a espacialidade, a mobilidade e os fluxos.

Seguindo o autor, a temporalidade contemporânea configura a crise da experiência moderna do tempo, que se manifesta na transformação profunda da estrutura temporal, no culto ao presente, no debilitamento da relação histórica com o passado e na confusão dos tempos que nos prende à simultaneidade do atual.

A espacialidade se decupa em múltiplos espaços: o espaço habitado do território feito de proximidade e pertencimento, o espaço comunicacional que tecem as redes eletrônicas, o espaço imaginado da nação e de sua identidade, o espaço da cidade moderna com a subjetividade que emerge da nova relação com a cidade e dos modos de sua apropriação.

A mobilidade, do trânsito incessante das migrações e das navegações virtuais dos internautas, nos traz o aparecimento das novas figuras de sensibilidade. E os fluxos que, como os dos migrantes que provocam desordens sociais e políticas na cidade, também são 
os fluxos de imagens, informação, das imagens, linguagens e escrituras virtuais, que desestabilizam a cultura letrada e escolar. A tecnologia digital desloca os saberes modificando tanto o estatuto cognitivo como institucional das condições do saber, conduzindo a um forte borramento das fronteiras entre razão e imaginação, saber e informação, arte e ciência, saber especializado e conhecimento comum.

A primeira grande síntese sobre as mediações foi formulada no livro Dos meios às mediações, lançado em 1987. Entretanto, a despeito da notável repercussão dessa obra, algumas vozes têm incitado o autor a escrever outro livro que respondesse à inversão desse título, isto é, Das mediações aos meios, a fim de "reequilibrar", no binômio, o peso da comunicação que teria sido subsumida pela cultura. Apesar de não concordarmos com o reducionismo que subjaz a essa proposta, talvez o autor tenha, de fato, aceito a incitação, pois o que temos visto, nos seus escritos dos últimos anos, é um notável esforço em oferecer pistas para elucidar ("entre-ver", como diz ele), cada vez mais, as relações entre meios e mediações. 0 que nos conecta ao debate epistemológico atual nos estudos latino-americanos de comunicação (LOPES, 2014).

Devido ao adensamento teórico dado à noção de tecnicidade, vale a pena fazermos algumas reflexões sobre a sua importância para o alargamento do estatuto teórico e metodológico da pesquisa de comunicação nos países latino-americanos.

Através da noção de tecnicidade, é possível entender a técnica como constitutiva, como dimensão imanente de uma noção antropológica de comunicação. Tomamos esta expressão não no sentido habitual de imputar essa visão à disciplina Antropologia, mas no sentido gramsciano do elementarmente humano. A necessidade da categoria tecnicidade se justifica, pois, no que ocorre hoje com a comunicação, não se dá a devida conta à noção grega de techné, que remetia à destreza, à habilidade de fazer, mas também de argumentar, de expressar, de criar e de comunicar através de formas materiais. Destreza essa que se atualiza com base nos novos modos de lidar com a linguagem. No entanto, caminhou-se para a noção de técnica como aparato, como objetivação da techné nas máquinas ou nos produtos. Nem um nem outro desses sentidos de técnica parecem ser suficientes, hoje. Porque na técnica há novos modos de perceber, ver, ouvir, ler, aprender, novas linguagens, novos modos de expressão, de textualidades e escrituras. 0 sentido da tecnicidade não se relaciona à ideia de mero aparato tecnológico, mas à competência na linguagem (MARTÍNBARBERO, 2004), às materialidades no discurso que remetem à constituição de gramáticas que dão origem a formatos e produtos midiáticos. A tecnicidade não é da ordem do 
instrumento, e sim dos saberes, da constituição de práticas produtoras de inovações discursivas, dos modos de percepção social. Afasta-se, portanto, da noção de técnica como mero aparato, recuperando o original sentido do termo grego techné. Haveria uma espécie de intermediação como experiência comunicativa, ou seja, de muitas interfaces entre os diferentes meios e destes nos diferentes espaços comunicativos do consumo e da criação. 0 que está aí implícito é a recusa do sentido instrumental de tecnologia tão sedimentada nos estudos de comunicação.

Reconhecer a envergadura que a tecnicidade tem hoje, não mais como instrumento, mas incrustada na estrutura mesma do conhecimento e da vida cotidiana, é uma pista metodológica forte que nos dá Martín-Barbero.

É possível transportar essa ideia desenvolvida acerca dos meios tradicionais para a lógica da sociedade em rede multiconectada, que traz, especialmente por meio do uso do computador e do celular, o acesso às novas mídias digitais. Novas formas de ação e novos tipos de relacionamentos sociais emergiram por meio do desenvolvimento dos meios de comunicação, permitindo novos modos de interação. Há pouco tempo restrito às classes socioeconômicas privilegiadas, esse mundo digital chega aos que têm menor poder aquisitivo e cria massa de consumo para essas tecnologias. Dentre outros fatores, isso decorre muito especialmente da competitividade tecnológica e dos usos da tecnicidade (MARTÍN-BARBERO, 2001), por onde passa hoje em grande medida a capacidade de inovar e de criar. Porque a tecnicidade é menos assunto de aparatos que de operadores perceptivos e destrezas discursivas. Tratar-se-ia de uma tecnicidade cognitiva e criativa (SCOLARI, 2008), porque confundir a comunicação com as técnicas e os meios resulta tão deformador como pensar que eles sejam exteriores e acessórios à comunicação.

\section{Considerações finais}

A incorporação dessas mediações nos estudos de comunicação dá origem a novos lugares metodológicos. A apropriação dos mapas pelo pesquisador depende da estratégia metodológica que adotar em uma dada pesquisa empírica, de modo que a escolha possa recair em determinadas mediações, e não em outras, dependendo do destaque que ganham na abordagem analítica. Desde a pesquisa sobre a recepção de telenovela (LOPES; BORELLI; RESENDE, 2002), que se tornou referência de trabalho empírico com base na metodologia das mediações, vem se demonstrando que os mapas barberianos devem ser usados estrategicamente nas pesquisas de comunicação. 
Sendo o objeto de estudo, por exemplo, um determinado produto comunicacional (telejornal, telenovela), a partir desse formato industrial, o pesquisador pode acionar elementos de sua linguagem televisiva em articulação com lógicas da produção explorando a tecnicidade. Também poderá articulá-lo às competências de recepção através por meio das mediações da ritualidade ou da socialidade. Trata-se, então, da elaboração de uma específica estratégia de uso dos mapas das mediações para sua pesquisa empírica.

\section{Referências}

BASTOS, Marco Toledo. Medium, media, mediação e midiatização: a perspectiva germânica. In: JANOTTI JUNIOR, Jeder; MATTOS, Maria Ângela; JACKS, Nilda (Org.). Mediação \& midiatização. Salvador: Edufba, 2012.

LOPES, Maria Immacolata Vassallo de. Mediação e recepção. Algumas conexões teóricas e metodológicas nos estudos latino-americanos de comunicação. MATRIZes, São Paulo, v. 8, n. 1, p. 65-80, 2014.

LOPES, Maria Immacolata Vassallo de; BORELLI, Silvia Helena Simões; RESENDE, Vera da Rocha. Vivendo com a telenovela mediações, recepção, teleficcionalidade. São Paulo: Summus, 2002.

MARTÍN-BARBERO, Jesús. De los medios a las mediaciones. Comunicación, cultura y hegemonia. Barcelona: Gustavo Gili, 1987. Obra com a primeira introdução.

MARTÍN-BARBERO, Jesús. Dos meios às mediações. Comunicação, cultura e hegemonia. 2. ed. Rio de Janeiro: UFRJ, 2001. Obra com a primeira introdução.

MARTÍN-BARBERO, Jesús. De los medios a las mediaciones. Comunicación, cultura y hegemonia. 5. ed. Bogotá: Convenio Andrés Bello, 1998. Obra com a segunda introdução.

MARTÍN-BARBERO, Jesús. De los medios a las mediaciones. Comunicación, cultura y hegemonía. Barcelona: Anthropos e Universidad Autónoma Metropolitana de México, 2010a. Obra com a terceira introdução.

MARTÍN-BARBERO, Jesús. Introducciones de los medios a las mediaciones. Bogotá: Centro de Competencia en Comunicación para América Latina; Fundación Friedrich Ebert, 2010b.

MARTÍN-BARBERO, Jesús. As formas mestiças da mídia. Revista Pesquisa FAPESP, São Paulo, n. 163, set. 2009a.

MARTÍN-BARBERO, Jesús. Ofício de cartógrafo. São Paulo: Loyola, 2004.

MARTÍN-BARBERO, Jesús. Uma aventura epistemológica. Entrevista por Maria Immacolata Vassallo de Lopes. MATRIZes, São Paulo, v. 2, n. 2, 2009b. 
MARTÍN-BARBERO, Jesús; MUNHOZ, Sonia (Coord.). Televisión y melodrama: géneros y lecturas de la telenovela en Colombia. Bogotá: Tercer Mundo, 1992.

SCOLARI, Carlos. Hipermediaciones: Elementos para una teoría de la comunicación digital interactiva. Barcelona: Gedisa, 2008.

VATTIMO, Gianni. A sociedade transparente. Lisboa: Relógio d’Água, 1992.

\title{
Jesús Martín-Barbero and the essential maps to understanding communication
}

\begin{abstract}
The work of Jesús Martín-Barbero is known for carrying out dislocations and ruptures. Shifts from the traditional places where the questions are asked. Ruptures with the reductionist and manichaean responses "to the right and to the left". The result can be summarized in a work of theoreticalmethodological construction known as nocturnal map, a cartography to explore the mediations - that is a milestone from which to study the new complexities in the relations between communication, culture and politics. The article has epistemological and methodological content, with respect to the concepts and processes of mediation. With this aim, we analyze the various methodological maps of the mediations that have accompanied the changes of the structural relations between communication and society and led to the improvement of the theory of mediations.
\end{abstract}

\section{Keywords}

Mediations. Maps. Jesús Martín-Barbero. Methodology. Theory. 